\title{
Correction to: Eviction, Health Inequity, and the Spread of COVID-19: Housing Policy as a Primary Pandemic Mitigation Strategy
}

\author{
Emily A. Benfer • David Vlahov • Marissa Y. Long • \\ Evan Walker-Wells • J. L. Pottenger Jr • Gregg \\ Gonsalves • Danya E. Keene
}

Published online: 25 January 2021

(C) The New York Academy of Medicine 2021

\section{Correction to: J Urban Health. https://doi.org/10.1007/s11524-020- 00502-1}

As a result of an error during the publication process, the middle initial of coauthor Danya E. Keene was incorrectly presented in this article as originally published as "A.". The original article has been corrected.

Springer Nature regrets the error.

Publisher's Note Springer Nature remains neutral with regard to jurisdictional claims in published maps and institutional affiliations.

The online version of the original article can be found at https://doi. org/10.1007/s11524-020-00502-1

\author{
E. A. Benfer $(\bowtie)$ \\ Wake Forest University School of Law, 1834 Wake Forest Road, \\ Winston Salem, NC 27109, USA \\ e-mail: benfere@wfu.edu \\ D. Vlahov \\ Yale School of Nursing, New Haven, CT, USA
}

M. Y. Long

Columbia University Mailman School of Public Health, New York, NY, USA
E. Walker-Wells · J. L. Pottenger Jr,

Yale Law School, New Haven, CT, USA

G. Gonsalves

Yale School of Public Health, Yale Law School, New Haven, CT, USA

\section{E. Keene}

Yale School of Medicine, Yale School of Public Health, New Haven, CT, USA 